\title{
Erratum to: Study on properties of hydrophobic associating polymer as drag reduction agent for fracturing fluid
}

Lei Wang ${ }^{1} \cdot$ Dan Wang ${ }^{1} \cdot$ Yiding Shen $^{1} \cdot$ Xiaojuan Lai $^{1} \cdot$ Xing Guo $^{1}$

Published online: 3 April 2017

(C) Springer Science+Business Media Dordrecht 2017

Erratum to: J Polym Res (2016) 23: 235

DOI 10.1007/s10965-016-1129-8

The original version of this article unfortunately contained a mistake. The affiliation of the authors was incomplete. The right affiliation should be "College of Chemistry and Chemical Engineering, Shaanxi University of Science and Technology, Xi' an 710021, China”. The revised complete affiliation is also shown below.

The online version of the original article can be found at http://dx.doi. org/10.1007/s10965-016-1129-8

Xiaojuan Lai

3578466@163.com

1 College of Chemistry and Chemical Engineering, Shaanxi University of Science and Technology, Xi'an 710021, China 